\title{
ETHzürich
}

\section{Catalytic Synthesis of N-}

Unprotected Piperazines,

Morpholines, and Thiomorpholines

from Aldehydes and SnAP

\section{Reagents}

\section{Journal Article}

Author(s):

Luescher, Michael U.; Bode, Jeffrey W.

Publication date:

2015-09-07

Permanent link:

https://doi.org/10.3929/ethz-b-000260405

Rights / license:

In Copyright - Non-Commercial Use Permitted

Originally published in:

Angewandte Chemie. International Edition 54(37), https://doi.org/10.1002/anie.201505167 


\section{Catalytic Synthesis of $\mathbf{N}$-Unprotected Piperazines, Morpholines and Thiomorpholines from Aldehydes and SnAP Reagents**}

\section{Michael U. Luescher and Jeffrey W. Bode*}

\begin{abstract}
Commercially available SnAP (Stannyl (Sn) Amine Protocol) reagents allow the transformation of aldehydes and ketones into a variety of $\mathrm{N}$-unprotected heterocycles. By identifying new ligands and reaction conditions, we have realized a robust catalytic variant that expands the substrate scope to previously inaccessible heteroaromatic substrates and new substitution patterns. It also establishes the basis for a catalytic, enantioselective process through the use of chiral ligands.
\end{abstract}

Saturated N-heterocycles are privileged scaffolds for the preparation of bioactive small molecules as they offer advantages including improved solubility, bioavailability, and pharmacokinetics. $^{[1,2]}$ Their use is currently limited by poor commercial availability and the paucity of methods for their preparation, particularly for mono- and di-C-substituted variants. In seeking to provide a cross-coupling approach for the rapid synthesis of substituted, saturated $\mathrm{N}$-heterocycles, we recently disclosed a cross-coupling approach from SnAP (Stannyl (Sn) Amine Protocol) reagents and aldehydes. This operationally simple process provides facile, one-step access to $C$-substituted thiomorpholines, ${ }^{[3]}$ morpholines, piperazines,${ }^{[4]}$ diazepanes and other medium-ring heterocycles ${ }^{[5]}$ and spirocyclic structures (Figure 1). ${ }^{[6]}$ Many of these SnAP reagents are now commercially available and SnAP chemistry is finding widespread use in industry.

Despite the outstanding substrate scope and operational simplicity of SnAP reagents, we have identified two major limitations. First, SnAP chemistry has so far required stoichiometric $\mathrm{Cu}(\mathrm{OTf})_{2}$, which both decreases efficiency and limits the possibilities of an enantioselective process. The need for stoichiometric copper is also at odds with our current mechanistic hypothesis, which postulates an overall redox neutral reaction. ${ }^{[3,5]}$ We attributed the need for stoichiometric copper to product inhibition - a common obstacle for metal catalyzed reactions in which the products are more basic than the starting materials. ${ }^{[7]}$ Second, aldehydes with proximal heteroatoms do not undergo cyclization. This is of special interest as the elusive 2-(pyridine-2-yl)piperazines and related scaffolds are often found in bioactive small molecules. ${ }^{[8]}$

[*] M. U. Luescher, Prof. Dr. J. W. Bode

Laboratory of Organic Chemistry

Department of Chemistry and Applied Biosciences

ETH Zurich, Vladimir-Prelog-Weg 3, 8093 Zurich (Switzerland)

E-mail: bode@org.chem.ethz.ch

Homepage: http://www.bode.ethz.ch

[*] Financial support was provided by the ETH Research Grant (ETH12 11-1) and the European Research Council (ERC Starting Grant No. 306793 - CASAA). The authors acknowledge the LOC Mass Spectrometry Service, the LOC NMR Service, the Small Molecule Crystallography Center of ETH Zurich for the X-ray measurement, and Thomas Pieth for experimental assistance.

Supporting information for this article is available on the WWW under http://dx.doi.org/

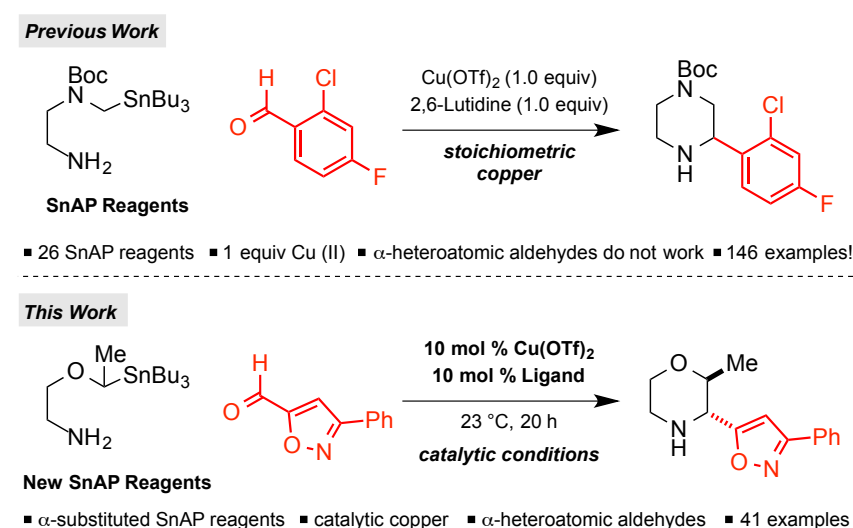

Figure 1. SnAP reagents for the synthesis of $\mathrm{N}$-heterocycles from aldehydes and ketones.

We now report the identification of ligand accelerated SnAP reactions that operate with catalytic amounts of copper and also further expand the substrate scope, including $\alpha$ heteroaromatic aldehydes. We also introduce $\alpha$-bis(substituted) SnAP reagents for the synthesis of 2,3-substituted $\mathrm{N}$ heterocycles, a new product class in SnAP chemistry (Figure 1), and demonstrate the viability of this system for catalytic, enantioseletive $\mathrm{N}$-heterocycle synthesis.

We postulated that product inhibition - rather than mechanistic considerations - precluded the use of catalytic amounts of copper, as experiments with $20 \mathrm{~mol} \%$ copper gave only about $20 \%$ yield (Table 1 , entries $1-3$ ). Heating to $90{ }^{\circ} \mathrm{C}$ in the absence of ligand increased conversion, but we found these conditions to have poor substrate scope (entry 4). As deactivation can often be reversed by additives or by a change in the ligand, we initially focused on ligand screening. A survey of ligands often used in copper catalyzed reactions, such as phenanthrolines, bipyridines, or phosphines, showed no catalytic activity (entries 5-9). ${ }^{[9]}$ Surprisingly, only a single ligand class Box ligands - showed appreciable catalysis and we established that $20 \mathrm{~mol} \% \mathrm{Cu}(\mathrm{OTf})_{2}$ in combination with $20 \mathrm{~mol} \%$ 2,2-bis(4phenyl-2-oxazolin-2-yl) propane (L8) promoted full conversion (entry 10). Further optimization focusing on the reaction temperature and solvent revealed two crucial parameters: (1) the integrity of the catalyst ${ }^{[10]}$ and (2) an increased amount of HFIP (1,1,1,3,3,3-hexafluoro-2-propanol). ${ }^{[11]}$ Heating the reaction to induce turnover was detrimental for catalytic activity (entry 11), a counterintuitive observation that we attribute to enhancement of ligand exchange between the bis(oxazoline) ligand L8 and the unprotected product. With HFIP as the sole solvent, we were able to reduce the catalyst loading to $5 \mathrm{~mol} \%$ (entry13). ${ }^{[11]}$ Based on literature precedents, ${ }^{[3,7,12]}$ we attribute the beneficial effect of increased HFIP, a solvent of broad utility due to strong hydrogen-bond donor abilities, ${ }^{[12,13]}$ to the complexation of the Nheterocycle product, thereby promoting turnover of the Lewis acidic copper catalyst (Figure 2). 
Table 1. Reaction optimization and ligand screening..$^{[14]}$

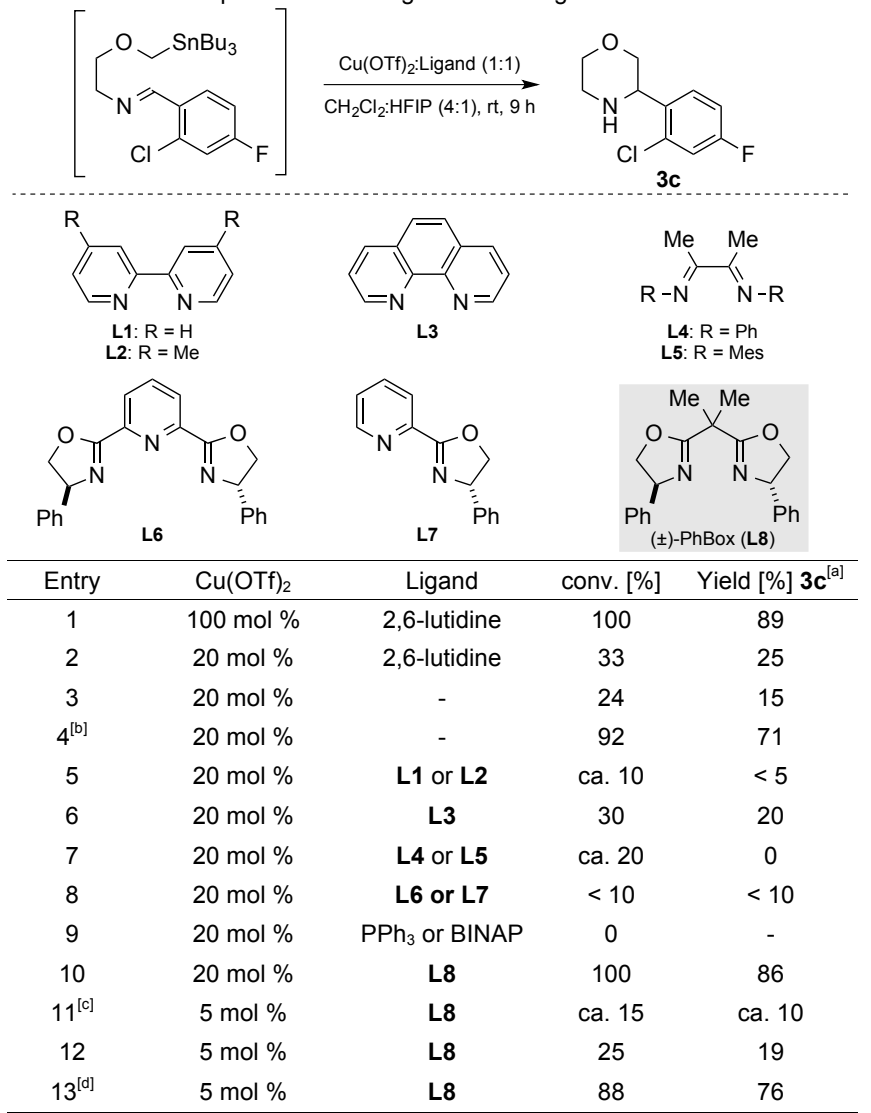

[a] NMR yield with 1,3,5-Trimethoxybenzene as internal standard. [b] Reaction performed at $90^{\circ} \mathrm{C}$. [c] Reaction performed at $45^{\circ} \mathrm{C}$. [d] HFIP as solvent.



Figure 2. Proposed catalytic cycle for copper catalyzed cyclization.

The catalytic conditions provided morpholines and thiomorpolines from the corresponding SnAP reagents, giving the majority of products in excellent yields from aromatic, heteroaromatic, and branched aliphatic aldehydes. We were pleased to find that - unlike the stoichiometric variant - all regioisomers of pyridinecarboxaldehydes and related heteroaromatic aldehydes were excellent substrates, an outcome that we attribute to the superior ligand and increased amount of HFIP. For some substrates, such as those containing additional coordinating heteroatoms, a higher catalyst loading (20 mol \%) was beneficial. Substrate specific optimization is also possible; for example in the gram-scale synthesis of 3c using $5.0 \mathrm{mmol}$ of SnAP M 1 and $5 \mathrm{~mol} \%$ catalyst loading. A few limitations remain including mesityl aldehyde $(3 \mathrm{~m})$ or aliphatic substrates prone to enamine formation (4k), which give mostly protodestannylated side products (Scheme 1).

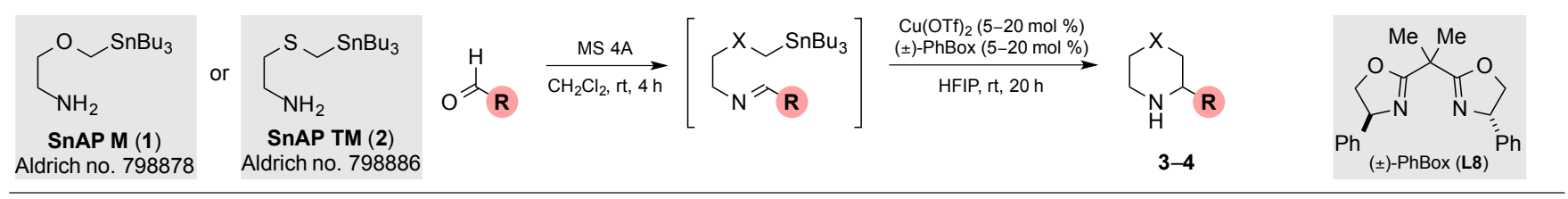<smiles>COc1ccc(C2COCCN2)cc1</smiles>

3a, $82 \%[a]$<smiles>c1ncc(C2COCCN2)cn1</smiles>

3b, $76 \%[b]$<smiles>Fc1ccc(C2COCCN2)c(Cl)c1</smiles><smiles>O=[N+]([O-])c1cccc(C2COCCN2)c1</smiles>

3c, $77 \%[\mathrm{a}],(74 \%)^{[\mathrm{c}]}$<smiles>Cc1cc(C2COCCN2)no1</smiles><smiles>CCOC(=O)C1COCCN1</smiles><smiles>O=C(c1ccccc1)N1CCC(CC2COCCN2)CC1</smiles>

$3 i, 62 \%{ }^{[b]}$ 3j, $67 \%[\mathrm{a}]$

$$
\text { 3k, } 60 \%[\mathrm{a}]
$$

3I, $32 \%[a]$<smiles>FC(F)(F)c1ccc(C2CSCCN2)cc1</smiles><smiles>c1cc(C2CSCCN2)ccn1</smiles>

$4 e, 66 \%\left[{ }^{[b]}\right.$<smiles>[13CH3]</smiles><smiles>Cn1c(C2CSCCN2)nc2ccccc21</smiles>

4h, $57 \%$ [b]<smiles>c1ccc(C2COCCN2)nc1</smiles><smiles>c1cncc(C2COCCN2)c1</smiles>

$3 e, 68 \%[b]$<smiles>Clc1ccc(C2CSCCN2)cc1</smiles><smiles>c1cc(C2COCCN2)cs1</smiles>

3g, $73 \%[\mathrm{a}]$<smiles>Brc1ccccc1C1CSCCN1</smiles>
4c, $47 \%[b]$<smiles>c1cnn(-c2ccc(C3COCCN3)cc2)n1</smiles>
3h, $63 \%$ [a]<smiles>[AlH2]c1ccc(C2CSCCN2)cc1</smiles>
4b, $49 \%[$ [b]<smiles>COC(=O)C1CSCCN1</smiles><smiles>CC(C)C1CSCCN1</smiles>

$4 i, 54 \%[b]$

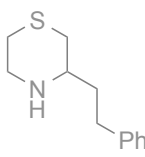

$4 k,<10 \%[b]$<smiles>N#Cc1cccc(C2CSCCN2)c1</smiles>

4d, $47 \%[\mathrm{~b}]$

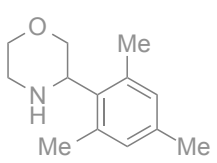

$3 \mathrm{~m},<10 \%[\mathrm{~b}]$

Scheme 1. Catalytic morpholine and thiomorpholine synthesis. Reactions were performed on a 0.5 mmol scale using 1.0 equiv SnAP reagent and 1.0 equiv aldehyde. Yields shown are of isolated, analytically pure compounds following chromatography. [a] $\mathrm{Cu}(\mathrm{OTf})_{2}(10 \mathrm{~mol} \%)$, ( \pm )-PhBox $(10 \mathrm{~mol} \%)$, HFIP (0.1 M). [b] $\mathrm{Cu}(\mathrm{OTf})_{2}(20 \mathrm{~mol} \%),( \pm)-\mathrm{PhBox}(20 \mathrm{~mol} \%), \mathrm{HFIP}(0.05 \mathrm{M})$. [c] $5.0 \mathrm{mmol}$ scale reaction: $\mathrm{Cu}(\mathrm{OTf})_{2}(5 \mathrm{~mol} \%),( \pm)-\mathrm{PhBox}(5 \mathrm{~mol} \%), \mathrm{HFIP}(0.1 \mathrm{M}), \mathrm{rt}, 36 \mathrm{~h}$. 
Curiously, the same conditions did not prove as effective for piperazine synthesis using SnAP Pip $\mathbf{5}$ as an increased amount of protodestannylated side products were observed. With these substrates, $10 \mathrm{~mol} \% \mathrm{Cu}(\mathrm{OTf})_{2}$ and $10 \mathrm{~mol} \%$ 2,6lutidine as ligand were found to be optimal, provided that an increased amount of HFIP was employed to promote turnover. Acetonitrile was identified as a beneficial additive that improved yields of the unprotected piperazines and also reduced the amount of protodestannylated side products (Scheme 2). ${ }^{[15]}$ Other additives such as $\mathrm{BF}_{3} \bullet \mathrm{Et}_{2} \mathrm{O}$, TMSOTf, $\mathrm{Sc}(\mathrm{OTf})_{3}$, or AgOTf did not have a significant effect, nor did the addition of fluoride sources ( $\mathrm{LiF}, \mathrm{KF}, \mathrm{CsF}, \mathrm{TBAF}, \mathrm{CuF}_{2}$ ) to facilitate possible transmetallation. Applying these conditions to SnAP M 1 or SnAP TM 2 resulted mostly in unreacted starting material, reinforcing the importance of the bis(oxazoline) ligand L8 for those transformations.

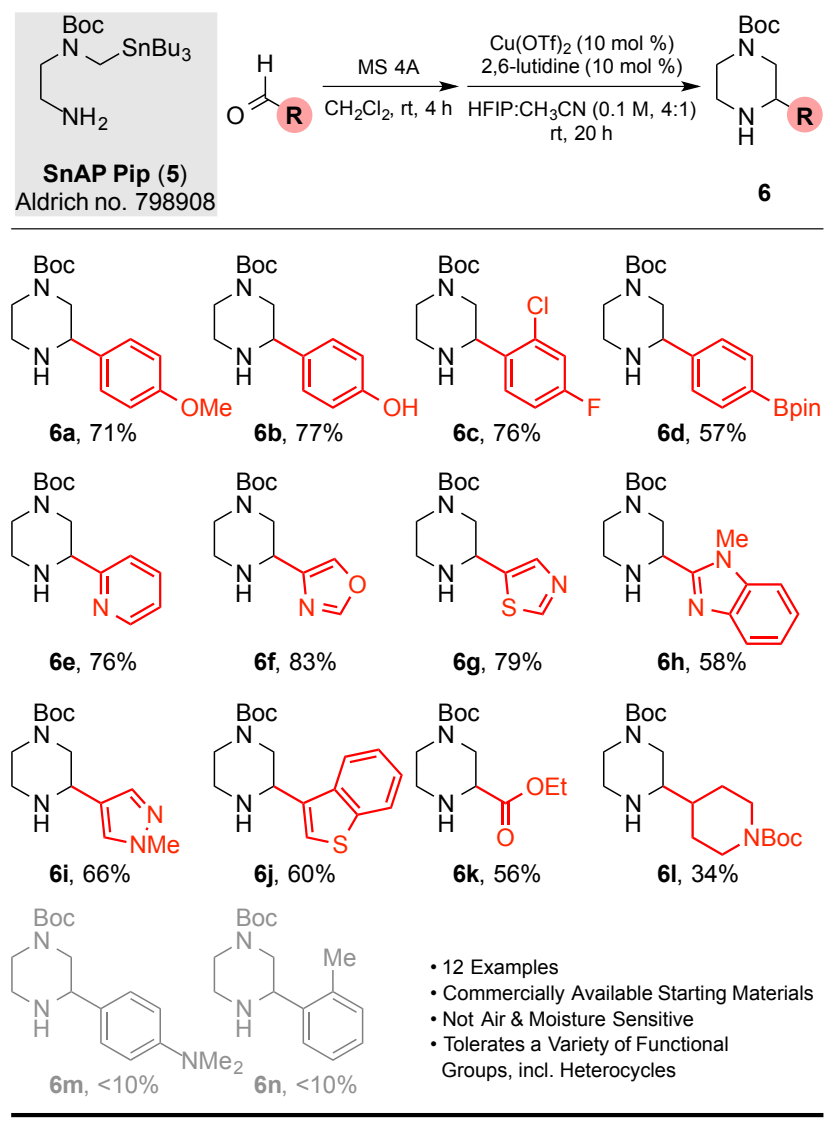

Scheme 2. Catalytic piperazine synthesis. Reactions were performed on a 0.5 mmol scale using 1.0 equiv SnAP reagent and 1.0 equiv aldehyde. Yields shown are of isolated, analytically pure compounds following chromatography.

These optimized conditions afforded a general protocol to the desired functionalized 1,4-diazacyclohexanes (6a-6I) using SnAP Pip 5 in good yields (Scheme 2). No special precautions were necessary for the reaction setup, as the reactions are not particularly air- or moisture sensitive. All experiments were performed using identical reaction conditions without substratespecific optimization. Aldehydes containing functional groups including esters (6k), aryl halides (6c), pinacol boronates $(\mathbf{6 d})$, and diverse heterocycles $(\mathbf{6} \mathbf{e}-\mathbf{6} \mathbf{j})$ enable the production of scaffolds suitable for further elaboration. The tolerance of these conditions towards heterocyclic carboxaldehydes containing heteroatoms in the ortho-position $(\mathbf{6 e}-\mathbf{6 h})$ is noteworthy as no product was observed with the previously reported stoichometric conditions using 1.0 equiv $\mathrm{Cu}(\mathrm{OTf})_{2} \cdot{ }^{[3-6]}$ The catalytic conditions were unfortunately not applicable to the formation of larger rings, such as diazepanes, which work well under stoichiometric conditions. Ketones also did not prove to be viable substrates under these conditions and afforded the desired spirocycles in low yields.

An advantage of SnAP chemistry is the ability to incorporate various substituents into the reagents themselves, facilitating the synthesis of substituted N-heterocycles, often as single diastereomers. ${ }^{[4,6 b]}$ To date, we have explored substitution at every position except that adjacent to the tributyltin moiety. To complete the study on ring substitution, we investigated the use of $\alpha$-bis(substituted) SnAP reagents 7 and $\mathbf{9}$, which would afford two adjacent stereocenters upon ring closure. Using the described standard conditions, these reagents coupled with representative aldehydes to provide 2,3-disubstituted morpholines $\mathbf{8 a , b}$ or $\mathbf{1 0 a - c}$ in good to excellent yields and high diastereoselectivity (Figure 3). The trans-relative configuration was confirmed by NMR and X-ray analysis. The excellent results with these more sterically demanding SnAP reagents to form vincinal substituted heterocycles is a promising approach to more congested structures difficult to form by other methods. ${ }^{[16]}$
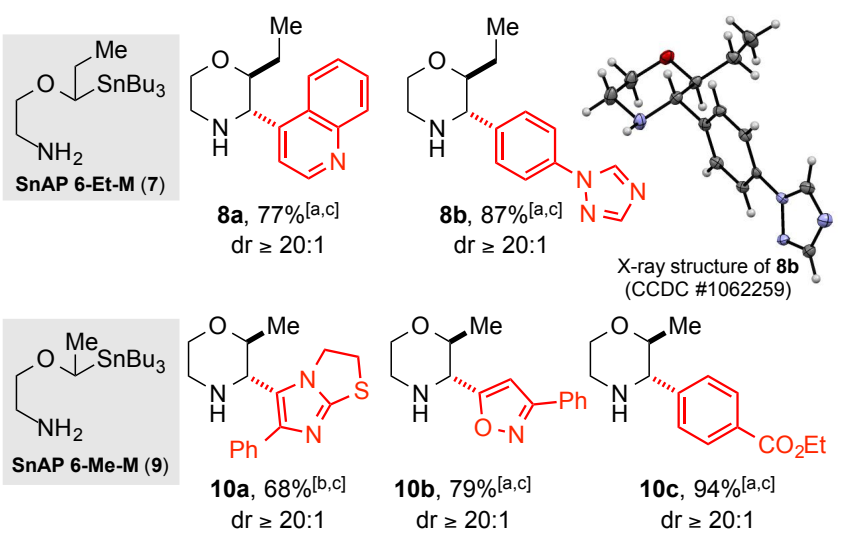

Figure 3. Synthesis of disubstituted morpholines. [a] Cu(OTf $)_{2}(10 \mathrm{~mol} \%)$, ( \pm )PhBox (10 mol \%), HFIP (0.1 M), 20 h, rt. [b] Cu(OTf) 2 (20 mol \%), ( \pm )-PhBox $(20 \mathrm{~mol} \%)$, HFIP $(0.05 \mathrm{M}), 20 \mathrm{~h}$, rt. [c] Relative stereochemistry was confirmed by X-ray analysis of $( \pm)-8 \mathbf{b}$; others were assigned by analogy.

The identification of substoichiometric reactions conditions presents the exciting opportunity to provide catalytic, ligandcontrolled, enantioselective variants. Catalytic asymmetric methods to generate optically active saturated N-heterocycles remain quite rare and have limitations such as complex linear precursors or the need for protecting groups. ${ }^{[17]}$ In preliminary experiments, we were pleased to find that using racemic SnAP 6-Et-M 7 in combination with enantiopure (S)-PhBox as ligand, enantioenriched 2,3-disubstituted morpholine 8c was delivered in $82 \%$ yield and a promising enantiomeric ratio of $80: 20$ (Scheme 3). Furthermore, the observed stereoconvergence supports our current mechanistic conjecture that the organostannane leads to a carbon radical upon oxidation by copper (II), ${ }^{[3,5]}$ as also observed by Falck. ${ }^{[18]}$ In contrast, most 
cross-coupling methods of stereodefined nucleophiles with copper exhibit stereospecific transmetallation and enantioenriched products are accessed only from non-racemic, configurationally stable precursors that are often difficult to access. ${ }^{[19]}$ Although improvements in the enantioselectivity are clearly needed, the observation of significant enantioinduction invites further studies on ligand optimization and investigations into the stereochemical determining step.

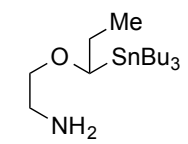

SnAP 6-Et-M (7)<smiles>Cc1ccccc1C=O</smiles>

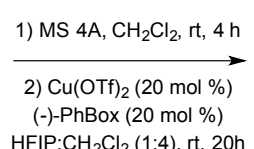
HFIP: $\mathrm{CH}_{2} \mathrm{Cl}_{2}(1: 4)$, rt, $20 \mathrm{~h}$

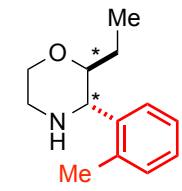

$8 c, 82 \%, d r \geq 20: 1$ $80: 20$ er $^{[a, b]}$
Scheme 3. Catalytic enantioselective morpholine synthesis. For additional examples see Supporting Information. [a] er (enantiomeric ratio) was determined by chiral HPLC analysis on the purified product. [b] Absolute stereochemistry not assigned.

In summary, we have identified catalytic protocols for the one-step synthesis of substituted, $\mathrm{N}$-unprotected piperazines, morpholines and thiomorpholines. This robust, air- and moisture tolerant protocol is a valuable addition to the SnAP chemistry and expands the substrate scope to include 2-(pyridine-2$\mathrm{yl})$ piperazines and related substrates. This work also introduces a new class of SnAP reagents, with substitution adjacent to the heteroatom, resulting in the diastereoselective synthesis of 2,3disubstituted $\mathrm{N}$-heterocycles. Our preliminary findings on a catalytic, enantioselective variant provide a promising start for the development of new routes to enantioenriched $\mathrm{N}$ heterocycles.

Keywords: cross-coupling $\cdot$ nitrogen heterocycles $•$ aldehydes $•$ homogeneous catalysis $\cdot$ SnAP reagents

[1] For selected reviews, see: a) R. D. Taylor, M. Maccoss, A. D. G. Lawson, J. Med. Chem. 2014, 57, 5845-5859; b) E. Vitaku, D. T. Smith, J. T. Njardarson, J. Med. Chem. 2014, 57, 10257-10274; c) S. D. Roughley, A. M. Jordan, J. Med. Chem. 2011, 54, 3451-3479; d) M. E. Welsch, S. a. Snyder, B. R. Stockwell, Curr. Opin. Chem. Biol. 2010, 14, 347-361; e) R. Wijtmans, M. K. S. Vink, H. E. Schoemaker, F. L. van Delft, R. H. Blaauw, F. P. J. T. Rutjes, Synthesis 2004, 641-662. For recent examples, see: f) L. Guandalini, M. V. Martion, L. Di Cesare Mannelli, G. Bartolucci, F. Melani, R. Malik, S. Dei, E. Floriddia, D. Manetti, F. Orlandi, et al., Bioorg. Med. Chem. Lett. 2015, 25, 17001704 ; g) K. Fukunaga, D. Sakai, K. Watanabe, K. Nakayama, T. Kohara, H. Tanaka, S. Sunada, M. Nabeno, M. Okamoto, K.-I. Saito, et al., Bioorg. Med. Chem. Lett. 2015, 25, 1086-1091.

[2] a) F. Lovering, Med. Chem. Commun. 2013, 4, 515-519; b) T. J. Ritchie, S. J. F. Macdonald, S. Peace, S. D. Pickett, C. N. Luscombe, Med. Chem. Commun. 2012, 3, 1062-1069; c) N. A. Meanwell, Chem. Res. Toxicol. 2011, 24, 1420-1456; d) T. J. Ritchie, S. J. F. Macdonald, R. J. Young, S. D. Pickett, Drug Discov. Today 2011, 16, 164-171; e) P D. Leeson, S. A. St-Gallay, M. C. Wenlock, Med. Chem. Commun. 2011, 2, 91-105; f) T. J. Ritchie, S. J. F. Macdonald, Drug Discov. Today 2009, 14, 1011-1020; g) F. Lovering, J. Bikker, C. Humblet, J. Med. Chem. 2009, 52, 6752-6756.

[3] C.-V. T. Vo, G. Mikutis, J. W. Bode, Angew. Chem. Int. Ed. 2013, 52, 1705-1708; Angew. Chem. 2013, 125, 1749-1752.
[4] M. U. Luescher, C.-V. T. Vo, J. W. Bode, Org. Lett. 2014, 16, 12361239.

[5] C.-V. T. Vo, M. U. Luescher, J. W. Bode, Nat. Chem. 2014, 6, 310-314.

[6] a) W.-Y. Siau, J. W. Bode, J. Am. Chem. Soc. 2015, 136, 1772617729; b) K. Geoghegan, J. W. Bode, Org. Lett. 2015, 17, 1934-1937.

[7] For a review, see: R. H. Crabtree, Chem. Rev. 2015, 115, 127-150.

[8] a) R. Kakarla, J. Liu, D. Naduthambi, W. Chang, R. T. Mosley, D. Bao, H. M. Micolochick Steuer, M. Keilman, S. Bansal, A. M. Lam, et al., J. Med. Chem. 2014, 57, 2136-2160; b) S. Mente, E. Arnold, T. Butler, S. Chakrapani, R. Chandrasekaran, K. Cherry, K. Dirico, A. Doran, K. Fisher, P. Galatsis, et al., J. Med. Chem. 2013, 56, 6819-6828; c) C. Gardelli, E. Nizi, E. Muraglia, B. Crescenzi, M. Ferrara, F. Orvieto, P. Pace, G. Pescatore, M. Poma, M. Del Rosario Rico Ferreira, et al., J. Med. Chem. 2007, 50, 4953-4975; d) V. Summa, A. Petrocchi, V. G. Matassa, C. Gardelli, E. Muraglia, M. Rowley, O. Gonzalez Paz, R. Laufer, E. Monteagudo, P. Pace, J. Med. Chem. 2006, 49, 6646-6649; e) F. Rondu, G. Le Bihan, X. Wang, A. Lamouri, E. Touboul, G. Dive, T. Bellahsene, B. Pfeiffer, P. Renard, B. Guardiola-Lemaitre, et al., J. Med. Chem. 1997, 40, 3793-3803.

[9] A. Alexakis, N. Krause, S. Woodward in Copper-Catalyzed Asymmetric Synthesis, Wiley-VCH, Weinheim, 2014.

[10] $\mathrm{Cu}(\mathrm{OTf})_{2}(5-20 \mathrm{~mol} \%),( \pm)-\mathrm{PhBox}(5-20 \mathrm{~mol} \%)$, HFIP $(2-4 \mathrm{~mL}), \mathrm{rt}, 6 \mathrm{~h}$. The reaction should be kept below $30{ }^{\circ} \mathrm{C}$ to prevent catalyst deactivation during the process of the reaction.

[11] For some examples using hexafluoroisopropanol or trifluoroethanol to overcome product inhibiton, see: b) H. F. Motiwala, C. Fehl, S. W. Li, E. Hirt, P. Porubsky, J. Aubé, J. Am. Chem. Soc. 2013, 135, 9000-9009; c) S. Kobayashi, H. Kiyohara, Y. Nakamura, R. Matsubara, J. Am. Chem. Soc. 2004, 126, 6558-6559; d) D. A. Evans, D. S. Johnson, Org. Lett. 1999, 1, 595-598; e) D. A. Evans, T. Rovis, M. C. Kozlowski, J. S. Tedrow, J. Am. Chem. Soc. 1999, 121, 1994-1995.

[12] For selected reviews, see: I. A. Shuklov, N. V. Dubrovina, A. Börner, Synthesis 2007, 2925-2943; b) J.-P. Bégué, D. Bonnet-Delpon, B. Crousse, Synlett 2004, 18-29.

[13] A. Berkessel, J. A. Adrio, D. Hüttenhain, J. M. Neudörfl, J. Am. Chem. Soc. 2006, 128, 8421-8426.

[14] A more detailed list can be found in the Supporting Information (Table S1).

[15] The reaction reaches full conversion using SnAP Pip (5) with protodestannylated side products as main constituents in applying the standard conditions reported in ref. 4 in catalytic manner $(10 \mathrm{~mol} \%$ $\mathrm{Cu}(\mathrm{OTf})_{2}: 2,6$-lutidine in HFIP: $\mathrm{CH}_{2} \mathrm{Cl}_{2}(1: 4,0.05 \mathrm{M})$ at rt). An increased amount of HFIP and $\mathrm{CH}_{3} \mathrm{CN}$ as a co-solvent was vital to obtain piperazines in meaningful yields.

[16] For an example of the addition of a sterically hindered tin nucleophile to an imine see: H. Kagoshima, K. Shimada, Chem. Lett. 2003, 32, 514515.

[17] For selected recent examples, see: a) K. M. Korch, C. Eidamshaus, D. C. Behenna, S. Nam, D. Horne, B. M. Stoltz, Angew. Chem. Int. Ed. 2015, 54, 179-183; Angew. Chem. 2015, 127, 181-185; b) Y. Numajiri, G. Jiménez-Osés, B. Wang, K. N. Houk, B. M. Stoltz Org. Lett. 2015, 17, 1082-1085; c) D. C. Behenna, Y. Liu, T. Yurino, J. Kim, D. E. White, S. C. Virgil, B. M. Stoltz, Nat. Chem. 2012, 4, 130-133; d) H. Zhai, A. Borzenko, Y. Y. Lau, S. H. Ahn, L. L. Schafer, Angew. Chem. Int. Ed. 2012, 51, 12219-12223; Angew. Chem. 2012, 124, 12385-12389; e) Y. Uozumi, A. Tanahashi, T. Hayashi J. Org. Chem. 1993, 58, 6826-6832. For reviews on catalytic asymmetric hydrogenations of heteroarenes, see: f) D. S. Wang, Q. A. Chen, S. M. Lu, Y. G. Zhou, Chem. Rev. 2012, 112, 2557-2590; g) Y.-G. Zhou, Acc. Chem. Res. 2007, 40, 1357-1366.

[18] R. K. Bhatt, J. Ye, J. R. Falck, Tetrahedron Lett. 1996, 37, 3811-3814.

[19] a) L. Li, C.-Y. Wang, R. Huang, M. R. Biscoe, Nat. Chem. 2013, 5, 607-612; b) J. R. Falck, P. K. Patel, A. Bandyopadhyay, J. Am. Chem. Soc. 2007, 129, 790-793; c) J. R. Falck, R. K. Bhatt, J. Ye, J. Am. Chem. Soc. 1995, 117, 5973-5982; d) J. Ye, R. K. Bhatt, J. R. Falck, J. Am. Chem. Soc. 1994, 116, 1-5. 
Layout 2:

\section{COMMUNICATION}

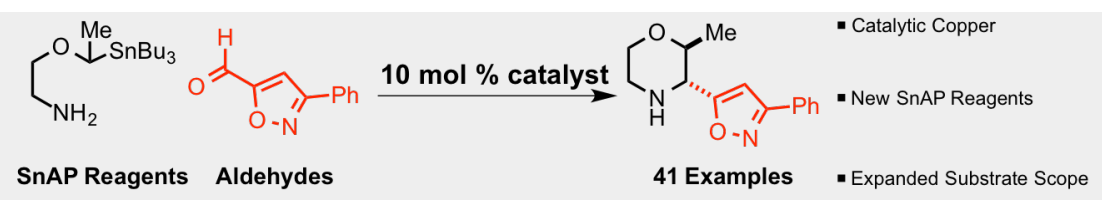

SnAPcat! The identification of new ligands and reaction conditions provides a robust catalytic protocol for the synthesis of $\mathrm{N}$-unprotected heterocycles using SnAP reagents. This catalytic variant expands the accessible substrate scope for the one-step access of substituted piperazines, morpholines and thiomorpholines and establishes the basis for a catalytic, enantioselective process through the use of chiral ligands.
Michael. U. Luescher, Jeffrey W. Bode*

Page No. - Page No.

Catalytic One-Step Synthesis of $\mathbf{N}$ Unprotected Piperazines, Morpholines and Thiomorpholines using SnAP Reagents 